\title{
Analysis of a low-voltage operating microgrid located in a residential area
}

\author{
Lucia-Andreea El-Leathey ${ }^{1,{ }^{*}}$, Rareș-Andrei Chihaia ${ }^{1}$, Ion Murgescu ${ }^{1}$, Gabriela Cîrciumaru ${ }^{1}$, and Adrian Nedelcu ${ }^{1}$ \\ ${ }^{1}$ National Institute for R\&D in Electrical Engineering ICPE-CA, Department of Efficiency in Energy Conversion and \\ Consumption, 313 Splaiul Unirii, Bucharest, Romania
}

\begin{abstract}
The paper aims at providing the analysis of domestic energy generation and consumption within residential areas. The topic of this study is twofold: theoretical and experimental by addressing aspects related to the operation of a microgrid connected to the low-voltage distribution grid. In order to achieve the power quality analysis for various scenarios, an appropriate testing stand was developed by using the Chauvin Arnoux CA 8435 analyser. There is envisaged the modelling and design of a mixed microgrid characterized by two line sections established by three main energy consumption nodes. There have been integrated several connection points related to the distributed generation sources and to the photovoltaic power plants, respectively, and also several supply points for the household end-users. 13 operation scenarios have been developed and recorded by analysing the voltage variation within the microgrid. Furthermore, the paper envisages the stabilization impact of the microgrid voltage variation in the presence of distributed generation sources.
\end{abstract}

\section{Introduction}

Even though the energy demand is usually met by centralized power generation, the current trends show that residential users are getting more and more interested in the use of renewable energy sources, distributed power generation, energy storage technologies and advanced automated systems for measurement and control [1]. Thus, microgrids consisting of standardized battery-plus-solar photovoltaic (PV) systems represent the major application that appeals to residential customers.

The advantages of residential microgrids regard aspects like environmental protection, diversification of energy generation sources, technological development and innovation, low cost of primary energy (especially solar energy) and the fact that they are not exhaustible. Another relevant aspect to the use of renewable energy sources takes into account the necessary restraints in order to ensure the safety of the electric power system [2].

In this respect, the integration of photovoltaic power plants has revealed an increasing interest in the recent years compared to other renewable energy sources [2]. Photovoltaic power plants and, implicitly, microgrids are considered one of the most important Smart Grids components, by including complex systems which ensure the efficient energy generation and use. Moreover, the energy generated by PV systems stands as an alternative solution which ought to be considered in the energy mix [3].
As far as the household energy consumption is concerned, residential areas use about $30 \%$ of the energy production. An important share of the residential sector is addressed by household appliances. This aspect requires the restriction of domestic energy sources (electricity, gas, hot water, heat, etc.), with positive effects on the urban infrastructure. An increase in the share of household appliances requires reanalysing the power supply system, with a focus on residential microgrids, photovoltaic energy conversion systems, three-phase power supply, relatively high electric current circuits, etc. [4].

Consequently, there is drawn the study of the energy generation impact near the consumer, by using photovoltaic power plants. This will allow the correct assessment of the distributed generation impact on the electrical equipment safety through measures which aim to keep the voltage level within the normative standards and implicitly to maintain reduced power losses for economic purposes [5].

The paper addresses the impact of a PV power plant on a low-voltage distribution network. In order to achieve the objective of the paper, the power quality indicators within a small-scale photovoltaic power plant were recorded and analysed when supplying low power consumers with linear or non-linear behaviour.

* Corresponding author: andreea.elleathey@icpe-ca.ro 


\section{Experimental setup}

ICPE-CA PV power plant is consisted of two photovoltaic systems, namely: the photovoltaic system A with a $14 \mathrm{kWp}$ installed power corresponding to a number of 56 modules, $250 \mathrm{~W}$ each, and the photovoltaic system B with $3.84 \mathrm{kWp}$ installed power corresponding to 16 modules, $240 \mathrm{~W}$ each [6-7].

The analysis of the selected PV power plant was achieved for both reduced and high solar irradiation. Next, the impact on a low-voltage electric distribution network was assessed. Furthermore, the power quality indicators were measured and analysed when supplying several household appliances.

In order to achieve the determination of the PV plant characteristics, a series of measurement equipment was used, thus developing the corresponding experimental stands. Figure 1 shows the testing stand for the measurement and acquisition of power quality indicators related to the PV power plant.

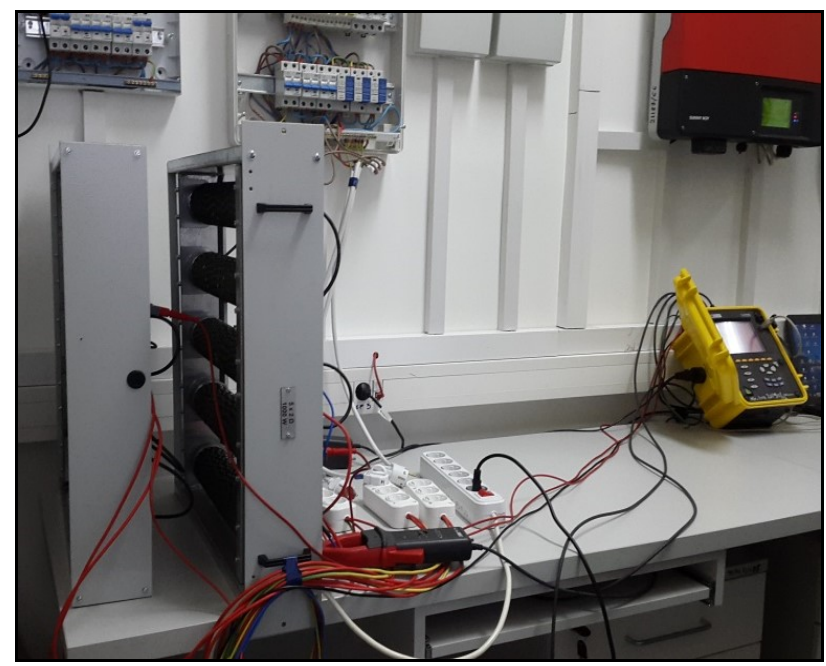

Fig. 1. The testing stand for the measurement and acquisition of power quality indicators related to the PV power plant.

The testing stand has aimed to model and develop a low-voltage test microgrid which is shown in Figure 2.

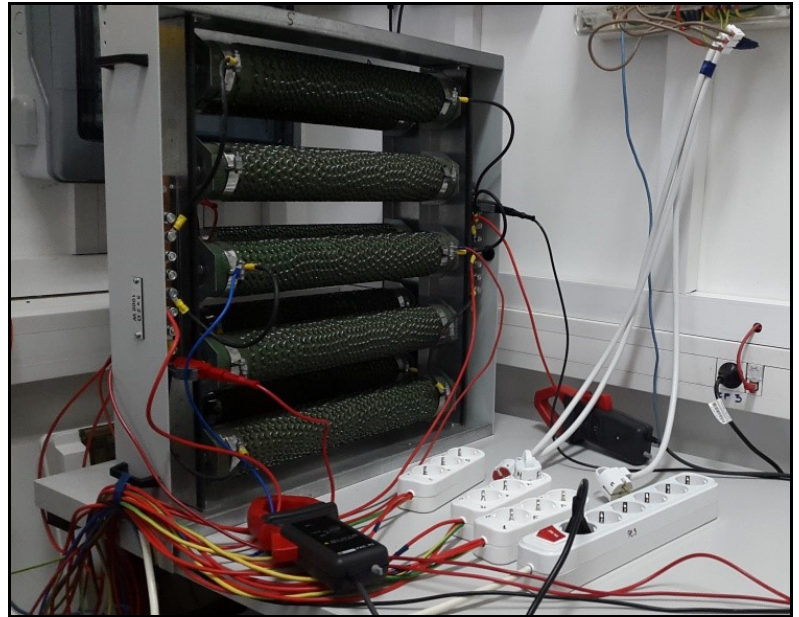

Fig. 3. The use of Chauvin Arnoux CA 8435 power quality analyser within the testing stand for the measurement and acquisition of power quality indicators related to the PV power plant.

The low-voltage test network shown in Figure 2 and 3 envisages an overhead power line located in the urban area, supplied by a 20/0.4 kV step-down transformer and described by the following longitudinal material parameters characteristic to a copper conductor:

- Cross section of the electrical conductor: $70 \mathrm{~mm}^{2}$;

E Electrical conductor length: $5.2 \mathrm{~km}$;

- Specific resistance of the electrical conductor:

$0.265 \Omega / \mathrm{km}$ (the equivalent specific resistance related to the entire conductor length is equal to $1.4 \Omega$ ).

- Specific reactance of the electrical conductor:

$0.0612 \Omega / \mathrm{km}$ (the equivalent specific reactance related to the entire conductor length is equal to $0.32 \Omega$ ).

The longitudinal material parameters of the conductor were established according to the NTE 007/08/00 technical norm for the design and execution of power distribution cables networks, applicable to the electric power lines operating at voltages up to and including $400 \mathrm{kV}$, managed by the economic operators from the energy sector [8].

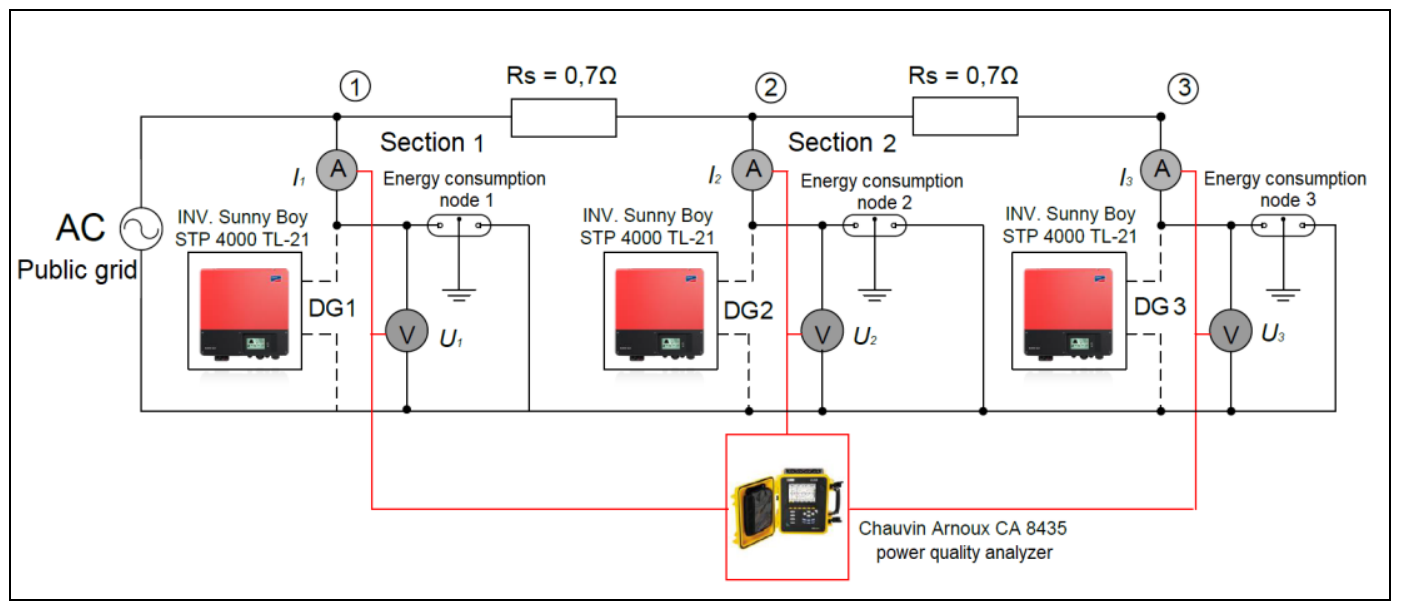

Fig. 2. Single-phase wiring diagram of the low-voltage test microgrid. 
The electrical grid is defined by 2 line sections established by 3 main nodes. The nodes correspond to the connection points of the distributed generation sources (in this case photovoltaic power plants) and to the power supply points of the household end-users. These nodes were considered as follows:

Node 1: established right next to the terminals of the transformer corresponding to point 1 of the PV power plant connection (DG1) and the power supply point 1 (Energy consumption node 1);

Node 2: established at $2.6 \mathrm{~km}$ from the transformer terminals corresponding to point 2 of the PV power plant connection (DG2) and the power supply point 2 (Energy consumption node 3 ), (specific resistance considered for the section $1 \approx 0,7 \Omega$ );

Node 3: established at the end of the line at a distance of $5.2 \mathrm{~km}$ from the transformer terminals corresponding to point 3 of PV power plant connection (DG3) and the power supply point 3 (Energy consumption node 3 ), (specific resistance considered for the section $2 \approx 0,7 \Omega$ ).

The low-voltage test microgrid described above and the two line sections were first modelled and then implemented by considering the simplified $\pi$ model, represented in Figure 4, where the shunt admittance (eq. (2)) is neglected $\left(Y_{a b}, Y_{b a} \approx 0\right)$ and only the series impedances (eq.(1)) are considered. The effect of capacitances was also ignored due to the presence of just low frequency signals $(f=50 \mathrm{~Hz})$ [9].

$$
\begin{aligned}
& \underline{Z}_{a b}=R_{a b}+j X_{a b} \\
& \underline{Y}_{a b}=G_{a b}+j B_{a b}
\end{aligned}
$$

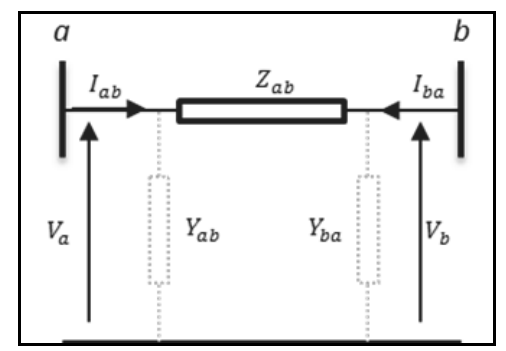

Fig. 4. Simplified $\pi$ model of an electrical grid [9].

Thus, the two low-voltage line sections were implemented in the testing stand by using cables and load resistors simulating the effect of the series impedances of the $\pi$ model.

As mentioned, the described low-voltage test grid was provided with 3 connection points of the distributed generation sources: DG1, DG2 and DG3. The connection points correspond to 3 distinct PV strings, connected to each inverter, and 3 supply points for household appliances. While the generated energy is entirely used for the consumers supply, the envisaged microgrid does not include any energy storage units.

In order to record and analyse the power quality indicators and the impact of photovoltaic power plants on the low-voltage distribution grids, Chauvin Arnoux CA 8435 power quality analyser was used.

Thus, for monitoring the nodes, both the current clamps and the voltage probes of the Chauvin Arnoux
CA 8435 were used. The power quality indicators monitored and recorded using the Chauvin Arnoux CA 8435 system took into account the harmonics of electric current and voltage and also the total harmonic distortion factor of electric current and voltage. Both the effective voltage and current values were recorded along with the active power flow passing the line.

Furthermore, 13 operation cases were proposed for the low-voltage test grid, as follows:

1. Resistive consumers connected to the 3 energy consumption nodes (1, 2 and 3$)$, powered only by the low-voltage grid. Three resistive appliances were used (1000 W fan heaters).

2. Resistive consumers connected to the 3 energy consumption nodes (1, 2 and 3 ) and a photovoltaic power plant connected to DG1 connection point.

3 . Resistive consumers connected to the 3 energy consumption nodes (1,2 and 3) and a photovoltaic power plant connected to DG2 connection point.

4. Resistive consumers connected to the 3 energy consumption nodes (1,2 and 3) and a photovoltaic power plant connected to DG3 connection point.

5. Resistive consumers connected to the 3 energy consumption nodes (1, 2 and 3 ) and a photovoltaic power plant connected to each connection point DG1 and DG3.

6. Resistive consumers connected to the 3 energy consumption nodes (1, 2 and 3 ) and a photovoltaic power plant connected to each connection point DG1 and DG2.

7. Resistive consumers connected to the 3 energy consumption nodes (1, 2 and 3 ) and a photovoltaic power plant connected to each connection point DG2 and DG3.

8. Resistive consumers connected to the 3 energy consumption nodes (1,2 and 3 ) and 3 photovoltaic power plants connected to DG1 connection point.

9. Resistive consumers connected to the 3 energy consumption nodes (1,2 and 3 ) and 3 photovoltaic power plants connected to DG2 connection point.

10. Resistive consumers connected to the 3 energy consumption nodes (1, 2 and 3 ) and 3 photovoltaic power plants connected to DG3 connection point.

11. Resistive consumers connected to the 3 energy consumption nodes (1,2 and 3) and 3 photovoltaic power plants connected to all connection points DG1, DG2 and DG3.

12. Inductive consumer ( $800 \mathrm{~W}$ vacuum cleaner) connected to the energy consumption node 3 and photovoltaic power plants connected to DG1, DG2 and DG3 connection points.

13. Inductive consumer ( $700 \mathrm{~W}$ microwave oven) connected to the energy consumption node 3 and photovoltaic power plant connected to DG1, DG2 and DG3 connection points.

When analysing the cases 2-13, the electrical consumers connected in various configurations were supplied both by the low-voltage grid and also by the photovoltaic power plants connected to the power system.

The 13 cases of operation related to the low-voltage test grid were subsequently integrated into operating 
scenarios for processing and analysis of the recorded data. The operating scenarios were set as follows:

- Scenario I: Study cases no. 1, 2, 3 and 4.

- Scenario II: Study cases no. 5, 6 and 7 .

E Scenario III: Study cases no. 1 and 11 .

E Scenario IV: Study cases no. 11, 12 and 13 .

\section{Results and discussion}

The power quality indicators related to the selected PV plant were recorded for the 13 operation cases of the low-voltage test network which were described above.

Figures 5 to 8 show the variation of the voltage level for the test grid nodes when analysing all the proposed scenarios. The variation was recorded for the entire conductor length, between both cable ends respectively ( $\mathrm{km} 0$ up to $\mathrm{km} \mathrm{5.2).} \mathrm{Thus,} \mathrm{the} \mathrm{following} \mathrm{figures} \mathrm{show}$ the voltage variation starting from the terminals of the transformer ( $\mathrm{km} 0$ of the line). It is considered that the voltage level of the power node $(\mathrm{km} 0)$ is variable, as it represents the supply voltage of the AC grid.

Figure 5 highlights the voltage variation for the study cases 1, 2, 3 and 4 which suggest the supply of the balanced loads connected to the three energy consumption nodes and associated to a system of symmetrical electrical currents. The successive connection of a photovoltaic power plant to the connection points DG1, DG2 and subsequently DG3 (study cases no. 2, 3 and 4) contributes to the improvement of the node's voltage level to which it is connected, as outlined in [10]. Thus, when analysing case 2 , the microgrid voltage is maximum for the DG1 connection point $(226 \mathrm{~V})$. Afterwards, the voltage decreases so at the end of the distribution line (Energy consumption node 3 ), the voltage reaches up to $219 \mathrm{~V}$. Similarly, for the cases 3 and 4, the effective voltage is maximum for DG2 and DG3 connection points. Case 1 is considered to be the most unfavourable, when the 3 consumers are supplied only by the low distribution public grid.

It is to be noted the significant voltage loss across the low voltage line and also the fact that the voltage variation from its rated value has negative consequences for both the normal operation of the household appliances and for the electrical grid. It is thus useful and sometimes compulsory to introduce additional voltage in the necessary nodes by using distributed generation sources for the purpose of regulating voltage in power transmission and distribution networks.

Similarly, as shown in Figure 6, the alternative connection of photovoltaic power plants to the connection points GD1, GD2 and subsequently GD3 according to scenario II (cases 5, 6 and 7) contributes to the improvement of the voltage level in the nodes to which they are connected. Scenario II was established in order to analyse the supply balanced loads which are connected to the three power points associated to a symmetrical electrical current system. It is noted that the most convenient case is represented by case 7 , which is provided with distributed generation sources connected to nodes 2 and 3. Moreover, it is shown that photovoltaic power plants can be used in order to supply the end-users located at long distances from the point of common coupling (PCC) and the transformer or even found at the power line terminal. It also follows that the most unfavourable case concerns the connection of distributed generation sources in the nodes located near the point of common coupling (Case 6), as there will still be disadvantages for the down line users who will benefit from low voltage.

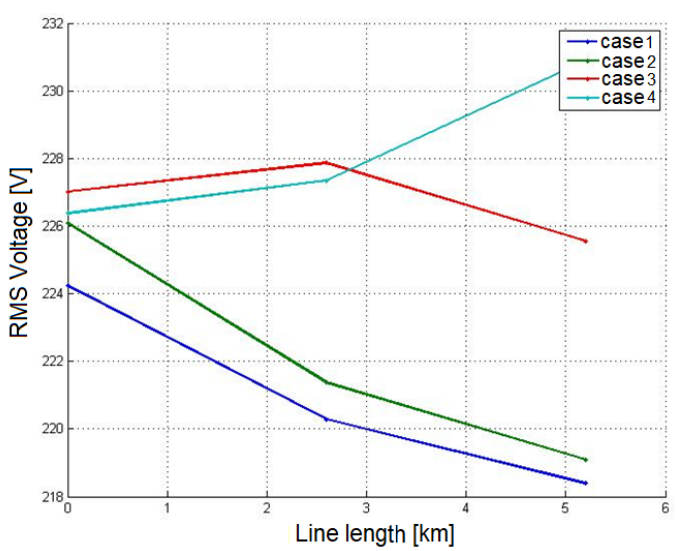

Fig. 5. The voltage variation related to the nodes of the electric test grid. Scenario I.

The aspects previously set out for Scenario II are valid for Scenario III as well which is shown in Figure 7. The photovoltaic power plants which are simultaneously connected to the GD1, GD2 and GD3 connection points (case 11) will lead to the increase of the entire grid's voltage. Moreover, it is worth noting the power quality improvement in comparison to case 1 when the appliances were powered only by the low-voltage electrical distribution grid. Case 1 is characterized by a significant voltage loss across the power line $(\approx 6 \mathrm{~V})$, in comparison to case 11 , when the voltage increases with up to $1 \mathrm{~V}$. The voltage increase across the line was no constant due to the unequal amounts of generated energy by each photovoltaic power plant.

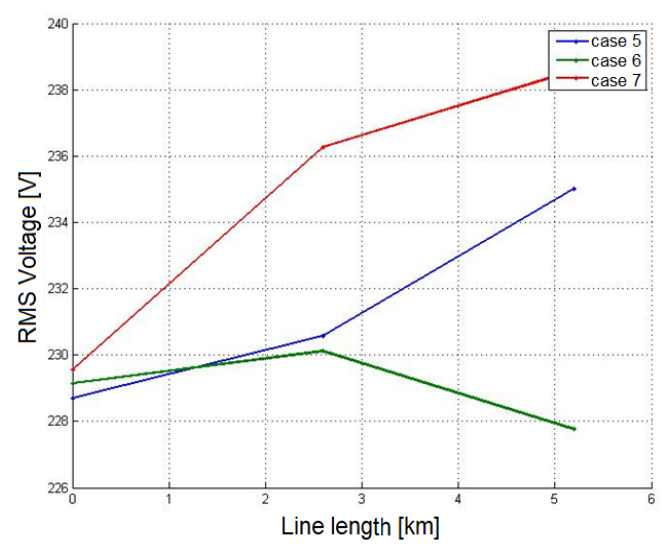

Fig. 6. The voltage variation related to the nodes of the electric test grid. Scenario II.

Figure 8 shows the variation of the voltage level for the test grid nodes when analysing scenario IV. It is to be observed that the variation of the voltage level in the 
electrical grid is not influenced by the type of supplied consumer.

Another aspect that has been noticed is the fact that in case 11, the presence of linear consumers with equal power at the energy consumption nodes leads to a constant voltage level in the electrical grid, maintained around the rated voltage of $230 \mathrm{~V}$.

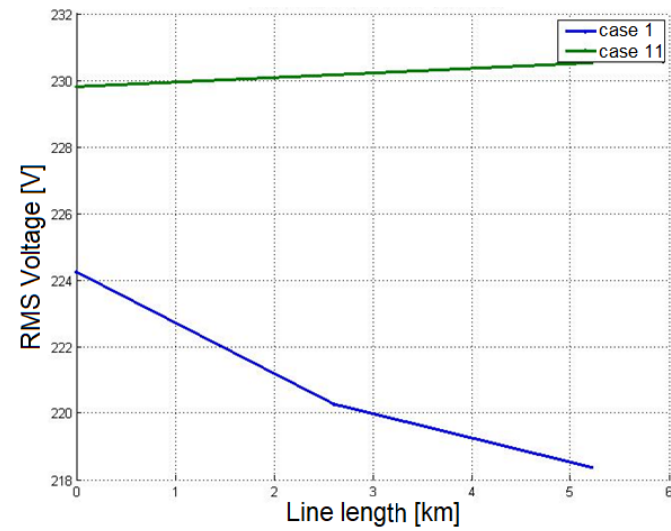

Fig. 7. The voltage variation related to the nodes of the electric test grid. Scenario III.

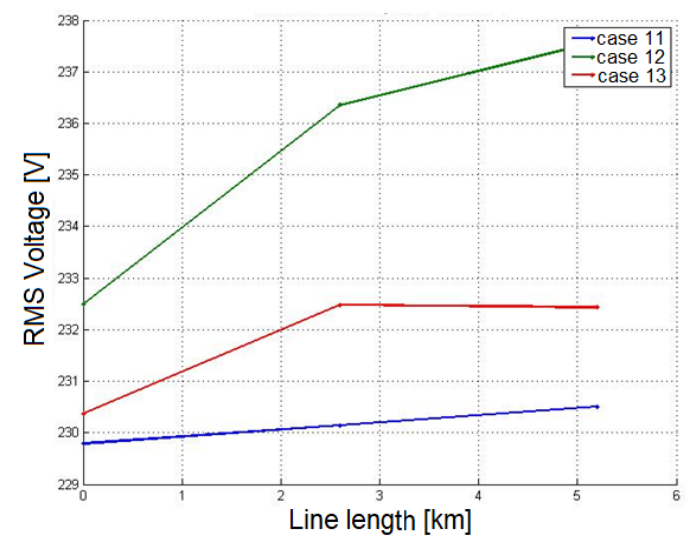

Fig. 8. The voltage variation related to the nodes of the electric test grid. Scenario IV.

Following the analysis of Figures 5 to 8, it appears that the presence of distributed generators contributes by improving the voltage level in the node in which they are connected. Depending on the power supplied by the generators, their impact affects the neighbouring nodes of the grid, the size of the influence zone being dependent on the injected power amount.

Furthermore, the maximum values of voltage harmonics, recorded as percentage of the fundamental voltage, were analysed. The measured values were below $2.8 \%$. It can be noticed that the $43^{\text {rd }}$ order harmonics and above are null. Also, both odd and even harmonics appear to be within the thresholds imposed by EN 50160 Standard [10]. As shown in Table 1, the $3^{\text {rd }}$ order harmonics are below the $5 \%$ threshold, the $5^{\text {th }}$ order harmonics below the $6 \%$ threshold, the $7^{\text {th }}$ order harmonics below the $5 \%$ threshold and the $9^{\text {th }}$ harmonics below the threshold of $1,5 \%$ and so on. The measured values meet the EN50160 Standard for all tested nodes in each of the 13 studied cases, independently of the photovoltaic power plants connection point or the type of supplied consumer.
Table 1. The comparison of the recorded voltage harmonics to the operating standard.

\begin{tabular}{|c|c|c|c|c|}
\hline \multirow{2}{*}{$\begin{array}{l}\text { Order of } \\
\text { the } \\
\text { recorded } \\
\text { harmonic }\end{array}$} & \multicolumn{3}{|c|}{$\begin{array}{l}\text { Harmonic value (\% of the } \\
\text { fundamental frequency) }\end{array}$} & \multirow{2}{*}{$\begin{array}{l}\text { Harmonic value } \\
\text { (\% of the } \\
\text { fundamental } \\
\text { frequency) } \\
\text { According to } \\
\text { EN50160 } \\
\text { Standard } \\
\end{array}$} \\
\hline & Node 1 & $\begin{array}{c}\text { Node } \\
2\end{array}$ & $\begin{array}{c}\text { Node } \\
3\end{array}$ & \\
\hline 2 & 0,4 & 0,2 & 0,3 & 2 \\
\hline 3 & 2,6 & 2,7 & 2,8 & 5 \\
\hline 4 & 0,3 & 0,4 & 0,2 & 1 \\
\hline 5 & 2,5 & 2,5 & 2,4 & 6 \\
\hline 6 & 0,3 & 0,3 & 0,1 & 0,5 \\
\hline 7 & 1,6 & 1,6 & 1,6 & 5 \\
\hline 8 & 0,1 & 0,1 & 0 & 0,5 \\
\hline 9 & 0,7 & 0,6 & 0,7 & 1,5 \\
\hline 10 & 0 & 0 & 0 & 0,5 \\
\hline 11 & 0,9 & 0,9 & 0,8 & 3,5 \\
\hline 12 & 0,1 & 0,1 & 0,1 & 0,5 \\
\hline 13 & 0,6 & 0,6 & 0,6 & 3 \\
\hline 14 & 0 & 0,1 & 0 & 0,5 \\
\hline 15 & 0,5 & 0,4 & 0,4 & 0,5 \\
\hline 16 & 0,1 & 0,1 & 0 & 0,5 \\
\hline 17 & 0,4 & 0,4 & 0,3 & 2 \\
\hline 18 & 0,1 & 0,1 & 0 & 0,5 \\
\hline 19 & 0,4 & 0,3 & 0,3 & 1,5 \\
\hline 20 & 0,1 & 0,1 & 0 & 0,5 \\
\hline 21 & 0,3 & 0,4 & 0,4 & 0,5 \\
\hline 22 & 0 & 0 & 0 & 0,5 \\
\hline 23 & 0,3 & 0,3 & 0,3 & 1,5 \\
\hline 24 & 0 & 0 & 0 & 0,5 \\
\hline 25 & 0,2 & 0,3 & 0,3 & 1,5 \\
\hline 26 & 0 & 0,1 & 0 & 0,5 \\
\hline 27 & 0,3 & 0,2 & 0,2 & 0,5 \\
\hline 28 & 0 & 0 & 0 & 0,5 \\
\hline 29 & 0,2 & 0,1 & 0,2 & 0,5 \\
\hline 30 & 0 & 0 & 0 & 0,5 \\
\hline 31 & 0,1 & 0,1 & 0,1 & 0,5 \\
\hline 32 & 0 & 0 & 0 & 0,5 \\
\hline 33 & 0,1 & 0,1 & 0,1 & 0,5 \\
\hline 34 & 0 & 0 & 0 & 0,5 \\
\hline 35 & 0,1 & 0,1 & 0,1 & 0,5 \\
\hline 36 & 0 & 0 & 0 & 0,5 \\
\hline 37 & 0,1 & 0,1 & 0,1 & 0,5 \\
\hline 38 & 0 & 0 & 0 & 0,5 \\
\hline 39 & 0 & 0 & 0 & 0,5 \\
\hline 40 & 0 & 0 & 0 & 0,5 \\
\hline 41 & 0,1 & 0 & 0 & 0,5 \\
\hline 42 & 0 & 0 & 0 & 0,5 \\
\hline 43 & 0,1 & 0 & 0 & 0,5 \\
\hline
\end{tabular}

\section{Conclusions}

In order to assess the impact of photovoltaic power plants on the quality indicators in low-voltage distribution networks, the theoretical and experimental analysis was carried out.

The testing of the selected microgrid, consisting of distributed (photovoltaic) generation sources and provided with connection to the electric low-voltage public distribution grid was achieved. Following the measurement and analysis of the nodes voltage across 
the grid, as well as of the voltage harmonics, it was found that:

a) In the absence of distributed energy sources, the voltage losses across the power line are significant (e.g. about $5 \mathrm{~V}$ for a resistive load of $3 \mathrm{~kW}$ ), resulting in a share of $\sim 2.3 \%$.

b). When connecting the distributed generation source and also depending on the connection point and configuration of the electrical grid, the voltage losses specified in section a) are compensated. As a result, the supply voltage of the end user stabilizes, the losses on the power line decreasing substantially.

This work was financially supported by the following grants of the Romanian Ministry of Research and Innovation (MCI): CCCDI-UEFISCDI, project number PN-III-P1-1.2-PCCDI2017-0391 / CIA_CLIM - Smart buildings adaptable to the climate change effects and also by NUCLEU 2018 Programme, project number PN18240201/ 2018 - Efficient energy conversion and storage systems for electrical engineering applications.

\section{References}

1. P.O. Kriett, M. Salani, Optimal Control of a Residential Microgrid, Energy 42, 1, 321-330, (2012)

2. N. Golovanov, H. Albert, S. Gheorghe, N. Mogoreanu, G.C. Lăzăroiu, Renewable energy sources in the power system, (A.G.I.R., 2015)

3. C. Nemeș, F. Munteanu, D. Astanei, Analysis of Grid-Connected Photovoltaic System Integration on Low-Voltage Distribution Network, JSE 7, 1, 9-14, (2016)

4. N. Golovanov, Chapter Energy efficiency in residential areas (to be published).

5. S. Abagiu, $\mathrm{PhD}$ Thesis Optimization of power systems with photovoltaic power plants, Transilvania University of Brașov, (Interdisciplinary Doctoral School, 2016)

6. L.A. El-Leathey, A. Nedelcu, R.A. Chihaia, G. Oprina, S. Nicolaie, D. Marin, Efficiency Assessment of an Urban Area Grid Connected PV Power Plant, Proceedings of the 10th International Symposium on Advanced Topics in Electrical Engineering, RES5, pp. 715-720 (2017)

7. L.A. El-Leathey, A. Nedelcu, M. Dorian, Power Quality Monitoring and Analysis of a GridConnected PV Power Plant, EEA 65, 3, pp. 26-33 (2017)

8. NTE $007 / 08 / 00$, Technical norm for the design and execution of power distribution cables (2008)

9. M. Armendariz, D. Brodén, N. Honeth, L. Nordström, A method to identify exposed nodes in low voltage distribution grids with High $P V$ penetration, IEEE Power \& Energy Society General Meeting, pp. 1-5 (2015)

10. Standard 50160:2011, Voltage characteristics in public distribution systems (2011) 